INSIGHTS INTO REGIONAL DEVELOPMENT

ISSN 2669-0195 (online) http://jssidoi.org/IRD/

2021 Volume 3 Number 2 (June)

http://doi.org/10.9770/IRD.2021.3.2(7)

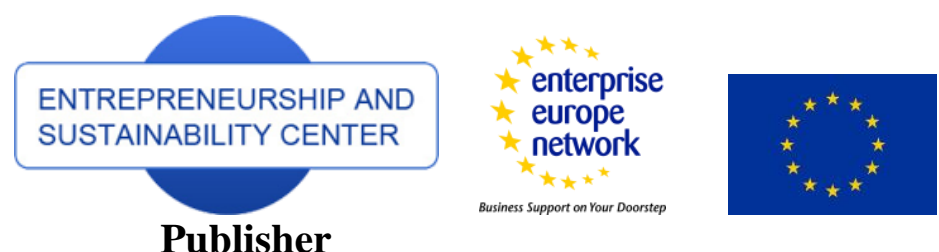

http://jssidoi.org/esc/home

\title{
A SYSTEMATIC THEORETICAL REVIEW ON SUSTAINABLE MANAGEMENT FOR GREEN COMPETITIVENESS
}

\author{
Nour Nassar ${ }^{1 *}$, Manuela Tvaronavičienė ${ }^{2}$ \\ ${ }^{1,2}$ Department of Business Technology and Entrepreneurship, Vilnius Gediminas Technical Iniversity (Vilnius Tech), \\ Sauletekio al. 11, Vilnius, Lithuania
}

E-mails: ${ }^{\text {Nour.Nassar@vilniustech.lt }}$ (Corresponding author); ${ }^{2}$ manuela.tvaronaviciene@vilniustech.lt

Received 10 February 2021; accepted 10 May 2021; published 30 June 2021

\begin{abstract}
Sustainable management for green competitiveness has been mentioned in the lasting researches based on various theories as to the transition theory, social responsibility theory (CSR), sustainable supply chain management theory (SSCM), the theory of planned behavior, and the contingency theory. Our purpose is to know which management theory is the most reliable in defining the intersection of management theories, sustainability, and green competitiveness. Therefore, a new interpretation must be parallel to cover all sustainability aspects: people, economics, and the environment. PRISMA-SCR (Preferred Reporting Items for Systematic reviews and Meta-Analyses for Scoping Reviews) methodology was used to develop a greater understanding of relevant terminology core concepts, and key items to report for scoping reviews.
\end{abstract}

Keywords: management theory; sustainable management; green competitiveness; competitiveness

Reference to this paper should be made as follows: Nassar, N., Tvaronavičienè, M. 2021. A systematic theoretical review on sustainable management for green competitiveness. Insights into Regional Development, 3(2), 267-281. http://doi.org/10.9770/IRD.2021.3.2(7)

Jel Classification: M15, O32

\section{Introduction}

Sustainable management for green competitiveness has been mentioned in the lasting researches based on various theories.

We will discuss in part I the most mentioned theories related to green competitiveness and sustainability as the transition theory, Social responsibility theory (CSR), sustainable supply chain management theory (SSCM), the theory of planned behavior, and the contingency theory.

Moreover, the literature has highlighted the Resource-based view (RBV) theory which will be described separately in Part II due to its high importance.

In the third part of this paper, we will answer the following question: 
INSIGHTS INTO REGIONAL DEVELOPMENT

ISSN 2669-0195 (online) http://jssidoi.org/jesi/

2021 Volume 3 Number 2 (June)

http://doi.org/10.9770/IRD.2021.3.2(7)

"Which management theory is the most reliable in defining the intersection of management theory, sustainability, and competitiveness?

\section{Sustainable management for green competitiveness is based on various theoretical aspects}

The previous literature emphasizes the main role of globalization in the success of small and small enterprises (Brodowska-Szewczuk, 2019; Castagna et al., 2020). Various factors preventing the internationalization of SMEs have been empirically studied to examine environmental, socioeconomic, operational, and organizational barriers. Previous research has found that small and medium-sized companies are more effective when they are using good internal capital or when they get benefits and/or funding from external sources (Castagna et al., 2020). Moreover, a new approach to research aims at exploring the main success factors which have a positive effect on the internationalization of SMEs brings up a discussion about the prospect of intensifying the mechanism of internationalization for SMEs based on daily business-to-business relations with corporations.

It is observed that the organizational dynamics of these companies have focused on the development of production, marketing, and competitiveness strategies to dominate the markets (Nevárez and Féliz, 2019).

It is in this scenario where social responsibility emerges as a proposal of differentiated management to be voluntary and establish a company-society relationship beyond the legal, focusing on the company recognizing its double act of both acceptance and negation, that is to say, accepts to promote the social good and refuses to harm (Nevárez and Féliz, 2019).

The theory of transition (Huguenin and Jeanneret) is not viewed as a modern philosophical growth paradigm rather as an interpretation and perceptual context from which traditional innovation theories and strategies can be reconsidered and extended based on a technology-producing and competitive approach to the development of society.

Although the transition theory (Huguenin and Jeannerat) can define the challenges and extent of a general shift, the innovation theory is also the practical and theoretical context for the recognition of resources. On the one hand, it can have a competitive and structural approach towards the production of social and economic benefits in markets that serve as knowledge and selection processes for supply-focused competition.

The transversal challenges (Huguenin and Jeannerat) of the global change of technology, economy, and society are captured in detail. It combines the straightforward, dynamic, multidimensional, co-evolutionary, and longterm aspects of sustainable goals within the current economic environment of competition, which is inevitably characterized by quantifiable growth objectives. Public policy should not only be seen as an exogenous catalyst of creativity (Huguenin and Jeannerat) but as an endogenous force for progress in value and growth that co-develops legitimizes, accepts, and enforces social values shared by social, economic, and political players. The theory of transition looks at long-range cycles of transformation involving a combination of technical, organizational, economic, social, cultural, and political changes. (Hermans, 1861) The innovation system perspective broadens the view beyond business actors directly involved in innovation processes, to a multitude of actors that can play a role within innovation processes such as governments, NGOs, research institutes but also consultancies, banks, and consumer organizations. Secondly, it pays particular attention to the influence of institutions (Hermans, 1861).

Valaei has proposed (Valaei, n.d.)A model of competitiveness for small and medium sized enterprises (SMEs) by exploring the systemic relationship between organizational structure, knowledge quality (KQ) dimensions, improvisational creativity, compositional creativity, and innovation in the emerging market in terms of sense- 


\section{INSIGHTS INTO REGIONAL DEVELOPMENT}

ISSN 2669-0195 (online) http://jssidoi.org/jesi/

2021 Volume 3 Number 2 (June)

http://doi.org/10.9770/IRD.2021.3.2(7)

making and organizational improvisational theories. These sense-making practices are also beneficial to the improvisational imagination, compositional imagination, and creative skills of SMEs. Centered on the theory of sensemaking (Dervin, 1998, 1992), this analysis involves the usability of KQ as another substructure of the interpreted KQ and expands the body of KQ literature and the theory of sense-making. (Valarie, n.d.)

A sustainable competitive advantage for SMEs requires that an operational KQ is based on a minor decentralized and relational system. The author (Valaei, n.d.) Provided a competition model for small and medium-sized companies, exploring the structural link in sense-making and organizational improvisational theories between institutional structure, information content dimensions, improvisational creativity, structural creativity, and innovation in emerging markets.

On the human level, the way individuals perceive a problem in a specific context is the way they see it (Paul and Morris, 2011).

Dervin et al. (2003) suggest that a person is made to realize reality, as he is incorporated into a certain context and moves across space and time. The structure of the organization will positively affect company innovation.

For example, looking at the relationship between organizational structure and competitive strategy, Claver Cortés et al. (2012) found that centralization and formalization, and sophistication are positively linked to the hybrid competitive strategies.

They found that a lean system encourages the process of making sense and that new understandings can be accomplished, thereby achieving a high level of KQ that results in improvisational imagination, compositional creativity, and innovation.

Among the retaken constructs are the four theories of social responsibility: corporate citizen theory (CCT), corporate social performance theory (CSD), shareholder value theory (TVA), and stakeholder theory (TAI). These theories have different approaches that go from the perspective that the company's social responsibility is only to achieve economic benefits and its commitment is only with the shareholders (TVA), to retake the theory of corporate citizenship (TCC) in which considers that the organization has rights and obligations towards society, which is the most relevant in this investigation. The theories mentioned above are related to the dimensions proposed by Boston College: the concept of corporate citizenship, strategic initiative, leadership, structure, social issues, and relationship with stakeholders, and transparency(Nevárez and Féliz,2019).

Other researchers (Belen and Nuria, 2017) also explored when and how multinationals incorporate the principles of sustainability and CSR into the business strategy. They saw how firms interact with sustainability and CSR behavior and analyzed the effect of their contact.

The findings show that the management and coordination of the principles of the CSR contribute to the competitiveness of multinational firms in line with the CSR instrumental theory in considering stakeholders' global demands. The findings appear to demonstrate that there are dangers but also benefits with CSR's contact (Belen and Nuria, 2017). If CSR principles are a fruitful engagement strategy, the partnership with stakeholders gets improved and the firm's credibility and perceptions with internal and external stakeholders get better (Belen and Nuria, 2017).

The idea of sustainable supply chain (SSCM), due to its relevance to financial, social, and business accountability for economic success, has received attention from industry and academia (Sampurna Panigrahi, Bahinipati, and Jain, n.d.). 


\section{INSIGHTS INTO REGIONAL DEVELOPMENT}

ISSN 2669-0195 (online) http://jssidoi.org/jesi/

2021 Volume 3 Number 2 (June)

http://doi.org/10.9770/IRD.2021.3.2(7)

As supply management is important for improving corporate productivity, a new analysis has evaluated the theoretical possibilities of SSCM and found that supply management is vital for enhancing organizational competitiveness.

Hence, sustainability concerns must be incorporated into the core functions of the, namely, purchasing, manufacturing, distributing, storing, warehousing, usage, recycling, and disposal (Linton et al., 2007). Business firms are under tremendous pressure to be able to sustain their existing SC due to recent trends of globalization, market changes, demand uncertainty, and economic challenges. Focusing only stressing on the internal efficiency of SC will be insufficient to gain a competitive advantage. If sustainability concepts are integrated into the core functions of a business firm's SC, it achieves a good market position in the global context (Khodakaramiet et al., 2015).

The writers have also taken economic aspects such as financial efficiency, expense minimization, strategic gains, and income into account (Winter and Knemeyer, 2013). Any key considerations, including collaborative knowledge exchange, optimized support for logistics, and viability, must be tackled to achieve economic resilience (Dubey et al. 2016). Many scholars have also indicated that the outlook of SCM is having a favorable impact on SSCM (Vachon and Klassen, 2008; Blome et al., 2014). SSCM is possible by financial stimuli, loans, and low pay intervals in the application of the SSCM energy-efficient activities. (Sampurna Panigrahi et al., n.d.)

Determining the cost across the sales cycle and long-term competitive approaches are cost-effective in defining, developing, and coordinating the SC goals and priorities of the business to their providers (Krause et al., 2009). Their findings have contributed to competitiveness advantages (Sampurna Panigrahi et al., n.d.)

Authors claimed that policymakers must encourage procurement from SMEs to boost local economic and social sustainable dimensions (Walker and Preuß 2008). Marketing campaigns need to be matched with SSCM strategies to build a sleek SC and resource performance (Brindley and Oxborrow 2014). The economic element is the judicious use of natural resources and a strong return on investment, relative to social and environmental considerations (Rumelt, 1974).

Ju, Wang, Cheng and Jia (2019) developed a research model for analyzing the sustainable efficiency effect factors of the supply chain logistics service. They were able to get the following unique results: the effect on the agility of the service supply chain on knowledge sharing lags and must mainly become the incorporation power of the supply chain. The findings show the value of the on-going exchange of information in LCCs. Logistics companies should develop a deep strategic relationship and form an association for knowledge sharing. Integrating skills is crucial to enhance the competitive efficiency of the supply chains, which are vulnerable to opportunistic behavior. Integrators should be prepared to enhance their actions and restrict opportunism.

To be able to achieve the highest consumer satisfaction with the lowest resource usage, they must improve the convergence of practical logistics firms, allowing the complete exercise of the strategy and cost advantages of various suppliers in their expertise. This will reduce the overall cost of transportation and increase the sustainable viability of the supply chain. Supporting logistics infrastructure building can by the government. The Government should have the necessary financial support of key logistics undertakings that meet the requirements for shipping, warehousing, storage, information facilities, and park infrastructure (Ju et al., 2019).

Contemporary international literature has highlighted the value of intellectual capital (IC), in particular in small and medium businesses because they have intangible assets as a foundation for their competitiveness as a core element of organizational performance (Asiaei and Jusoh, 2015; Jordão and Almeida, 2017; Novas et al., 2017), (Ngah and Ibrahim, 2009; Khalique et al., 2015; Vinícius, Jordão, Novas, and Gupta, 2020) 


\section{INSIGHTS INTO REGIONAL DEVELOPMENT}

ISSN 2669-0195 (online) http://jssidoi.org/jesi/

2021 Volume 3 Number 2 (June)

http://doi.org/10.9770/IRD.2021.3.2(7)

Researchers (Vinícius et al., 2020) indicated that K-Network plays a key role in creating the IC and enhancing corporate efficiency in small and medium-sized businesses. The findings (Vinícius et al., 2020) have also shown the strategic importance of people-to-business ties to monitor the mechanism of information and knowledge development and exchanged in the examined network.

K-Networks help small and medium-sized companies accomplish their objectives and develop interorganizational partnerships to access new tools, markets, and competencies (knowledge, expertise, and attitudes) (Muhammad et al., 2011; Jardon and Martos, 2012; Rantala and Ukko, 2018; Leminen et al., 2019).

For small and medium-sized businesses, the dedication to business networking is of vital importance for their survival, growth, advancement and competitiveness, sustainability, and efficiency. Networks have been widely recognized in recent years for effective, sustainable, and creative business results. Small and medium-sized businesses, although, also face obstacles and consume capital that pursues outcomes that are at some point regulating. In theoretical terms, IC is a company that is implicit and known in strategic distinctions. In the literature, the consensus was reached on the three dimensions of the IC: human capital, institutional capital, and relation capital. (Vinícius et al., 2020)

Scholars note that the ability to mobilize, integrate, and use a tangible or intangible tool of an organization strategically is a critical factor in improving market differentiation and competitiveness. Jardon and Martos (2012) explain that core skills only help to produce IC when they allow the organization to compete more effectively than its rivals (Vinícius et al., 2020).

The conclusions showed that IC is formed (in its three dimensions) as a result of a strategic combination of SMEs in a K-network and that IC mediates the role of IC in supporting improving their organizational performance, taking account of the improved financial outcomes observed, marketing development, productivity, efficiency, creativity, and competitiveness (Vinícius et al., 2020).

One strategic strategy is to encourage the growth of new enterprises in the industry. One of Finland's leading fields in the large field of economy is bioenergy growth and processing. (Kokkonen and Ojanen, 2018)

High success in organizations with multiple facilitators can be seen as assets to be developed by companies. These qualities will help businesses achieve fast growth in a sense and thus reclaim the top slots in the international rankings that they once enjoyed. Highly high investment in R\&D and the high technical and quality production capabilities of the Japanese business are important. This is very much in line with Japan's well-known ethos and history (Bhattacharya, Momaya, and Chandrasekhar Iyer, n.d.).

Previous researchers (Bezerra, Arruda, Laila, and Moroni, 2018) examined the value of sustainability practice as a moderator of the interactions between competition and efficiency in port operations, with growing exposure to sustainability in port operations.

Research findings (Bezerra et al., 2018) showed the role of SPs in providing outstanding port operations that dramatically moderate the relationship between productivity and efficiency and quality of service and production.

Other researchers (Huntley Lewis, 2019) highlighted the need for a speech about the successful use of environmental laws to affect the actions of industrial operators to achieve sustainable tourism. This dialogue is considered important in the sense of climate change and the challenge to tourism (Huntley Lewis, 2019). The stringency and value of legislation are often taken into account as it is logically believed that it will be an opportunity to keep firms successful if properly implemented (Huntley Lewis, 2019). 


\section{INSIGHTS INTO REGIONAL DEVELOPMENT}

ISSN 2669-0195 (online) http://jssidoi.org/jesi/

2021 Volume 3 Number 2 (June)

http://doi.org/10.9770/IRD.2021.3.2(7)

The literature has said very little about it and the importance of various practices to support sustainable growth as well as improved competition is still minimal. Sustainability is a new focus (Camisón, 2020). This sustainability dimension is understood by allowing current and future generations to develop stable and prosperous societies where human well-being prospers in the area of processes. While the prevailing theory is in the academic literature that sustainability can lead to long-term changes in competition, comprehensive research case studies are also needed to validate the strategy and to provide a theoretical framework for public-private policies adopted by tourism organizations (Camisón, 2020).

\section{Sustainable management for green competitiveness based on RBV theory and Porter's (1980) competitiveness, strategic theory, Dynamic capabilities (DC), and innovation}

The innovation system perspective broadens the view beyond business actors directly involved in innovation processes, to a multitude of actors that can play a role within innovation processes such as governments, NGOs, research institutes but also consultancies, banks, and consumer organizations. It pays particular attention to the influence of institutions as one of the factors that influence how the innovation game is played in different contexts (Hermans, 1861).

System perspective is an empirical framework to research technological progress as a dynamic mechanism of behavior and interaction between a diverse community of players engaged in information creation, sharing, and use (Hermans, 1861).

Large businesses need to search for new capabilities to achieve radical progress that varies from their current skills and know-how (e.g., Dewar and Dutton, 1986; Ettie et al., 1984; Green, Gavin and Aiman-Smith, 1995). Therefore, radical innovation companies and different ventures in themselves must face challenges and discontinuities such as markets, technology, organizations, and capital (Kodama, 2017).

\section{The importance of innovation based on RBV theory}

Changes are becoming more prominent in the 21 st century in market conditions affecting large businesses. Managers and company leaders face a wide range of challenges with the globalization of industry and the increasing number of operations in emerging markets, with disruptive technology, rapidly mature networking through economies and markets, and price and environmental problems. New business models that reform current regulations and fundamentally revitalize traditional goods and services are changing large companies' corporate strategy (Kodama, 2017).

Kodama introduces a strategic innovation model to achieve strategic innovation within a large organization, taking account of extensive DC studies, as the key driver of this framework is the idea of strategic innovation capabilities. (Kodama, 2017)

As strategy theory models for micro and organizational economics have been established resource-based theories focusing on autonomous capacity for businesses and organizations (e.g., Barney, 1991; Penrose, 1959; Richardson, 1972; Rumelt, 1984; Wernerfelt, 1984; Kodama, 2017).

Dynamically strategic innovation generates strategic placement by using new products, services, and business models and offers a complex view of a strategy that helps a large organization to preserve its competitiveness and generate sustainable growth (Kodama, 2017).

That is why big business must become creative companies that can improve their current roles (companies) through gradual innovation, while continuously renovating or destroying existing businesses through radical innovation. 


\section{INSIGHTS INTO REGIONAL DEVELOPMENT}

ISSN 2669-0195 (online) http://jssidoi.org/jesi/

2021 Volume 3 Number 2 (June)

http://doi.org/10.9770/IRD.2021.3.2(7)

DC theory has been developed, strengthened, and has become a fundamental theory in recent years (e.g., Teece, Pisano, and Shuen, 1997; Teece, 2007, 2014) that clarifies the mechanisms of sustained development through corporate strategic innovation (Hermans, 1861). DC is characterized by Teece et al. (1997, p. 516) as the ability of the organization to incorporate, create, and reconfigure internal, external, and rapidly change-based environments. They say that DC thus represents the ability of the company given path dependencies and market position to achieve new and creative forms of competitive advantage (Leonard-Barton, 1992).

Moreover, this interest in strategic theory has grown, according to other researchers, into a complex framework that represents the company's actual market. For instance, the DC theory is valued by O'Connor (2008). Eisenhardt and Martin (2000) and list a large number of key developments, including progressive developments, which have been developed over several years to several decades for slow (or very slow) markets (Kodama, 2017).

DC must not be confined to brand new firms, fast shifting markets, or drastic changes.

Researchers have exposed strategic and sustainable directions under these circumstances (Wong, Soh, and Chong, 2016). Does SCP impact competition strongly and sustainably? An affirmative response to this is given by the composite strategic analysis model, backed by the Market-based view (MBV) and RBV theories (Wong et al., 2016).

Two key hypotheses are supporting the conceptual model.

Internal resources - RBV. To define internal resources, RBV is a helpful approach (Warren, 2002). It is important to identify skills that are essential to the comparative edge of business success (Day, 1994) (Teng and Cummings, 2002). The resources would only be able to contribute to the achievement of competitive advantage if they met the four resource requirements (valuable, rare, non-substituted, and inimitable) (Newbert, 2008). Such services are typically a dynamic collection of identifying resources across the organization and ensure the organization of practical activities (Day, 1994; Wong et al., 2016).

The RBV qualities of uncommon (Bharadwaj, 2000), non-substantiality (Barney, 1991), and inimitability also fulfill the practical interaction and IT capability and include the combination of three resource properties, special historical circumstances, causal uncertainty, and social complexity (Wade and Hulland, 2004). The output of these attributes qualifies RBV as variables for practical participation and IT capability (Wong et al., 2016).

External resources - MBV. Business forces of the organization are largely based on systemic concepts, and business conditions which create a precious basis for a corporation to achieve a strategic edge in a competitive environment (Makhija, 2003). The methods are focused on financial success and activities (Wong et al., 2016).

The two factors are widespread rivals (potential entrants, replacements, and competition) and negotiation capacity (customer and supplier). Huo et al. (2008) proposed the emphasis on low cost and the emphasis on the distinction in two aspects of operations in terms of corporate strategies. The emphasis on low costs is described as an organization competing as the lowest-cost supplier. The emphasis on differentiation is described as the gap between its services and the services of its competitors in areas like quality and versatility, while cost is not the main strategic priority. The two reasons are intense competitiveness and bargaining ability (potential entrants, substitutes, and rivalry) (customer and supplier). Huo et al. (2008) suggested a focus on low cost and a focus on differentiation as regards business policy in two areas of operations. The accent on low cost is represented as a competing company as the lowest-cost provider. The emphasis on distinction is defined by the divide between its services and the services of its rivals in areas such as efficiency, speed, and flexibility (Wong et al., 2016).

Prior contributions to conventional, firm-based economic growth capabilities tend to undermine their capacity to implement wider environmental policies. However, policy planning for sustainable growth will also have a 


\section{INSIGHTS INTO REGIONAL DEVELOPMENT}

ISSN 2669-0195 (online) http://jssidoi.org/jesi/

2021 Volume 3 Number 2 (June)

http://doi.org/10.9770/IRD.2021.3.2(7)

positive impact on some of the investments in greenhouse gas mitigation initiatives. Besides, communities facing more competition for growth are more likely to combine strategy and success assessment to determine their environmental commitments. (Deslatte and Stokan, 2020)

Deslatte and Stokan found that city agencies can achieve improvements in sustainability by recognizing fungible operational skills that can be more readily reassigned to related roles. Moreover, strategic planning, which includes both economic growth and preservation efforts, will find further opportunities to exploit current capabilities. Moreover, cities situated in more dynamic urban growth environments should pay more attention to monitoring and controlling success to justify spending money on sustainable development efforts. Over-reliance on tax-incentive economic development strategies that also drain resource communities can weaken broader commitments to sustainable development (Deslatte and Stokan, 2020).

However, the analysis finds evidence that economic development strategic planning can positively influence some investments in GHG reduction efforts. Moreover, perceptions of competition for economic development positively mediate the relationship between the strategies governments develop to pursue sustainable economic development and the performance information they collect (Deslatte and Stokan, 2020).

Competitive competition between cities in metropolitan regions increases output assessment commitments (Deslatte and Stokan, 2017; Hawkins, 2014; Teske et al. 1993). Cities use sustainability investments to differentiate themselves from competitors; assessing the effect of these investments promotes branding and helps to validate actions by stakeholders. The ultimate hypothesis is that competitive competitiveness puts a higher emphasis on the demonstration of sustainability-related advantages, which could contribute to a better use of performance knowledge for decision-making on the distribution of capital. (Deslatte and Stokan, 2020)

Organizational synergies: the exploit the key competencies, assumption in public management research is that organizational capital can be diverted as administrators adjust current operations, efforts, energy, and resources to new priorities and activities (Frederickson 1996; Kearney and Meynhardt 2016; O'Toole and Meier 1999).

However, the existence of certain unique capital obligations makes them less adaptable. Levinthal and Wu (2010) suggest that the distinction between scale-free and non-scale-free capacities is an important way of interpreting organizational strategies. Scale-free capabilities, such as patents or computer operating systems, have low to no potential costs since having them in one way would not diminish the potential of anyone to do the same in another arena or operation. However, most operational capacities are non-scale-free and are congestible until dedicated (Deslatte and Stokan, 2020).

Competencies that can be extended to related tasks create beneficial synergies and are more likely to contribute to what Bryson, Ackermann, and Eden (2007) call central, distinctive competencies. Cities focus on non-scale-free skills as they employ employees or departmental staff to manage environmental programs through working groups or other structures (Feiock, Krause, and Hawkins, 2017; Krause 2013). Dedicated staff may prioritize and coordinate programs, co-ordinate departmental training on emerging technologies, promote stakeholder engagement, build success processes, and identify financing (Wang et al. 2012).

Prior analysis has found that strategic planning; involved and on-going administration is periodic rather than constant in policy development, execution, appraisal, and adaptation (Poister 2010). As a result, where success input is missing or disconnected from decision-makers, policy goals and objectives can be shelved. Bryson, Berry, and Yang (2010) also felt generic in this disconnect to obtain a strategic direction for work. Strategic management as a realistic philosophy needs further attention to the promotion of organizational learning and the acquisition of "strategic knowledge" (Bryson, Berry, and Yang 2010). 


\section{INSIGHTS INTO REGIONAL DEVELOPMENT}

ISSN 2669-0195 (online) http://jssidoi.org/jesi/

2021 Volume 3 Number 2 (June)

http://doi.org/10.9770/IRD.2021.3.2(7)

Increasing demands for strategic management frameworks are articulated by local governments as 'strategic level success management' (Poister 2010). The theory of public organization, based on capital, may explain how tactics structure and impact the success of organizations (Andrews, Beynon, and McDermott 2016).

A better picture is taken of drivers and obstacles to diversification through the linkage of strategic management literature on company capacity and diversification with systems of opportunities faced by public policymakers and managers. (Deslatte and Stokan, 2020)

The world of today, characterized by competition, calls on firms and managers to consider the market rapidly and to deliver goods and services that not only satisfy their demands but also aim to surpass their expectations. In this sense, businesses can build not only commodities but also product-service networks that involve connectivity, personnel, and expertise as well as deals. Strategic and architecture philosophy is a theory with a tremendous potential that poses itself both as project and management approach capable of finding and seizing resources to further form the offers and providing value to the public and create economic growth for the whole production chain. Bezerra (Bezerra et al., 2018)aims to focus on the possibilities of strategic design and branding, through the use of a product that is identifiable and earns revenue for developing and promoting solutions that improve and value users' experience. (Bezerra et al., 2018)

There is a broad diversity of ideas related to uncertainty. According to some scholars, human actions and ambiguity are the principal drivers of complexity. This system of dynamic complexity may be an organization, technology, or people. Human emotional intelligence and interpersonal behavior (Love, Edwards, and Wood, 2011) will research the dynamic relationships between individuals within an organization or mission and its effect on competition.

In the background of a documentary about the competitiveness of various nations, Frans Hermans developed a structure known as Porter's Diamond.

The concept behind the diamond is that competition, efficiency, and economic development in a particular location depend on the market climate.

This local background can be divided between the four sides of the diamond into four main elements:

-Factor conditions: technologies, and capital.

-Demand conditions from (technically sophisticated) customers.

-Links to related and supporting industries.

-Firm strategies, structure, and rivalry (Hermans, 1861, 2018).

Further interactions between these four variables are formed and intense, the larger the productivity of the firms concerned. Porter noted in his work The Competitive Advantage of Nations that the most competitive firms in a country frequently concentrate geographically in several locations, clusters.

The creation of new clusters to promote generic competition and growth was a small move from this viewpoint: the geographical clustering of firms enhances the interaction of all four diamond elements and is thus thought to be advantageous for regional development. The reason for attracting unique industries in some regions starts with how the endowments of a country or area relate to the requirements of an industry. Such factors include natural conditions (climate, ore) and the production of endowments (capacity, resources, and infrastructure). However, the factors alone are not entirely clear regarding regional domination; to a degree, such factors are mobile or can be imitated by other countries or regions.

The essence and scale of demand in the home country is the second factor for Porter. Large domestic markets are an opportunity for the growth of the industry. And when a wide home market expands before it can take root in 


\section{INSIGHTS INTO REGIONAL DEVELOPMENT}

ISSN 2669-0195 (online) http://jssidoi.org/jesi/

2021 Volume 3 Number 2 (June)

http://doi.org/10.9770/IRD.2021.3.2(7)

other parts of the world, experienced businesses are given enough opportunity to hunt for business abroad when saturation starts.

Competitiveness of the Home Industry, The fourth aspect of the "global diamond" model, is characterized by firm strategy, structure, and rivalry in the home industry.

This factor summarizes the competition structure of "five powers". The better the market at home, the more successful businesses would succeed worldwide.

This argument is proven by plenty of evidence. The fierce competition between German drug companies has made them a tremendous global market power.

And the solid domestic market share battle has enhanced Japanese car manufacturers' international competitive position(Hermans, 1861).

\section{Critics and limits of RBV theory vs Organisational theory ((i.e., institutional theory and upper echelon theory)}

The studies using RBV or CRBV to explain creative manufacturing activities or the distribution of TQMs usually do not capture the social context in which resource selection is set up, that is, in the field of corporate tradition and network relations and regulator pressures (Dubey et al., 2017).

Dubey adds research to the literature on motivations of adoption (Kennedy and Fiss 2009) from a sociological perspective, emphasizing the social integration of organizations and motivations which stem principally from a desire to appear legitimate to strong constituents and peer groups or external stakeholders.

His studies concentrate on the diffusion phases after adoption, however, and top managers must consider the degree of engagement they need, even after their company has effectively taken up TQM. In other words, once the complementation decision has been taken and the latest managerial innovation starts, top managers should remain involved until the innovation is completely disseminated by the company to produce the desired results.

Although Porter's work was very popular with politicians and professionals, in particular, the scientific community was considerably more critical. The lack of a consistent description of the borders of a cluster is one of the most frequently recorded criticisms of Porter's cluster theory. Clustering and agglomeration processes are partly natural processes when a set of sectors is formed in the vicinity of each other.

The cluster may be within one city (e.g., Wall, Street, the Financial Cluster) and may also cross urban, regional, and often even national geographical limits, depending on the form of economic operation. Thus, the choice of natural, geographical or administrative boundaries for a cluster is difficult and in many studies, it often results in arbitrary and arbitrative cluster limits.

Despite its analytical weaknesses, the existing bio-cluster policy literature treats bio-clusters like any other form of cluster. As a result, research focusing on competition, employment, and creativity dominates the literature. The view of bio clusters represents in this regard the more general view of the bioeconomy. The literature of Hermans concentrated on the mentioned bioeconomic aims such as developing awareness, jobs, and new business opportunities and disregarded sustainability issues and environmental advances which are also an indispensable part of the biological economy transition. The presence of transition theory in the study of bio clusters may provide an insight into this. (Hermans, 1861). 


\section{Results and conclusion}

To explore the world of competitiveness and sustainability, we adopted Preferred Reporting Items for Systematic reviews and Meta-Analyses for Scoping Reviews (PRISMA-SCR) to develop a greater understanding of relevant terminology core concepts, and key items to report for scoping reviews.

We started searching for the link between "sustainable management" and "management theory" using it as keywords and found 574 searches. Note that the Databases were exclusively WOS, KJD, RSCI, and SCIELO for the Timespan equal to the Last 5 years (2015 -2020) and we have limited our Search language to English. Since we got an important number of researches done in this field, we tried to go deeper to find the link between "management theory" "sustainable management "and "competitiveness".

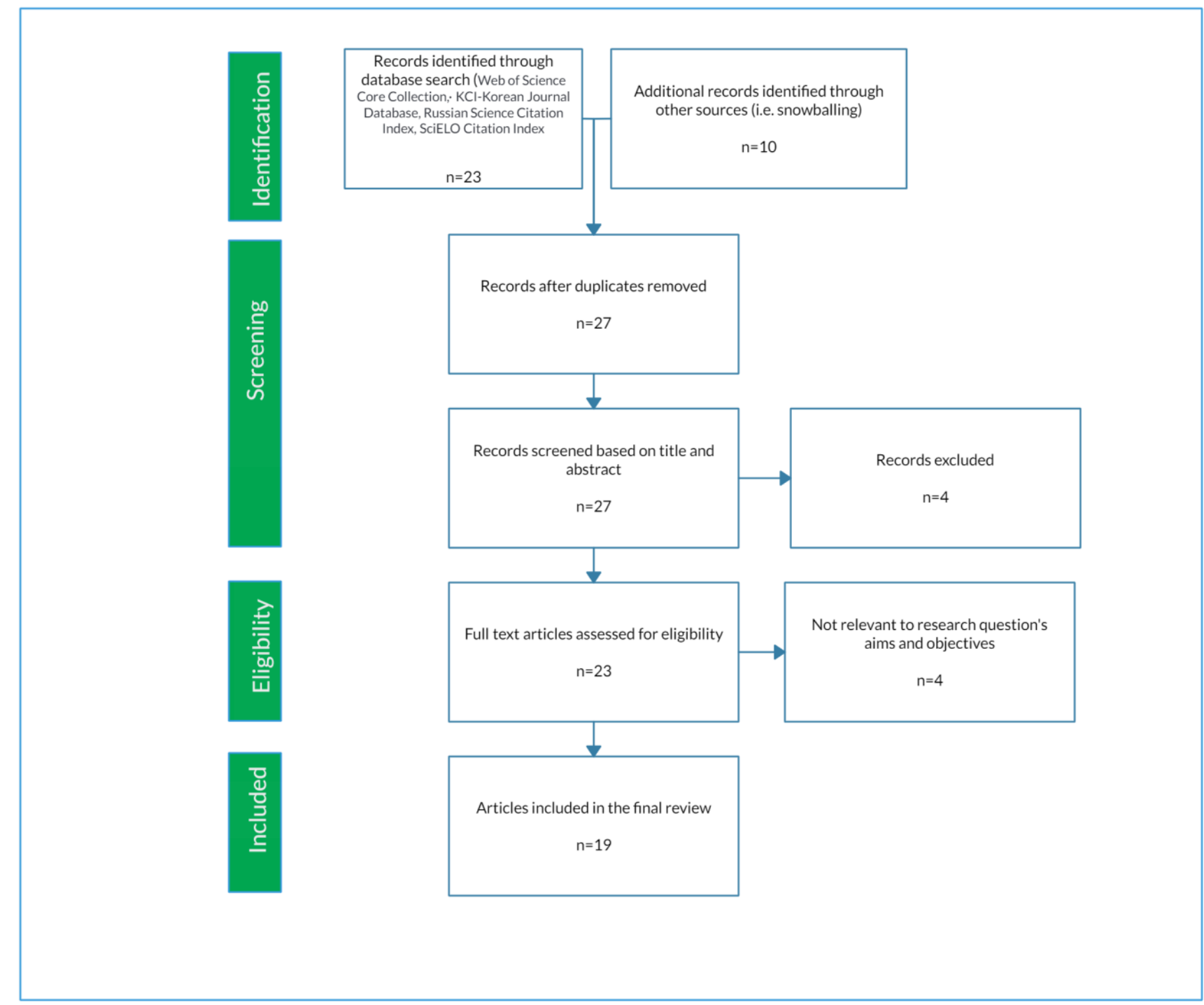

Figure 1. PRISMA-flow diagram - the link between management theory, sustainable management, and competitiveness created by the author. Note that the PRISMA 2009 Flow Diagram is From Moher D, Liberati A, Tetzlaff J, Altman D.G; PRISMA Group. Preferred reporting items for systematic reviews and meta-analyses: the PRISMA statement (as well see Appendix A, Table 1)

Source: created by the authors 
INSIGHTS INTO REGIONAL DEVELOPMENT

ISSN 2669-0195 (online) http://jssidoi.org/jesi/

2021 Volume 3 Number 2 (June)

http://doi.org/10.9770/IRD.2021.3.2(7)

Recent studies have highly focused on the intersection between management theory and sustainable management, where we found 574 results, which means $48 \%$ of the studies covered this topic. This indicates the importance of sustainable management from a theoretical viewpoint.

We could only detect the recent obvious management theories (46\%); as a result, 54\% of the sustainable management theories were left undetected.

Moreover, recent studies have also found a link between management theory and competitiveness. We could only detect the recent obvious management theories (46\%); as a result, 54\% of the sustainable management theories were left undetected.

Similarly, recent studies have also found a link between management theory and competitiveness.

Hence, which management theory, is the most reliable defining the intersection of management theories, sustainability, and green competitiveness?

Is it the administrative theory or another undetected management theory?

Based on the literature review that focused on systems management theory and sustainability, we found that out of the $46 \%$ detected management theories, the most studied management theories were consecutively Administrative theory $19 \%$, Human relations theory $12 \%$, and Contingency management theory $7 \%$.

We assumed at first that the administrative theory is the best describing the intersection between sustainability and competitiveness. Contrarily, our findings showed that RBV theory is the most significant management theory that contributes to sustainable management for green competitiveness as described in Fig 2. The percentages of management theories linked to sustainable competitiveness based on the latest literature review were RBV theory (40\%), Contingency theory (13\%), Administrative management theory (10\%).

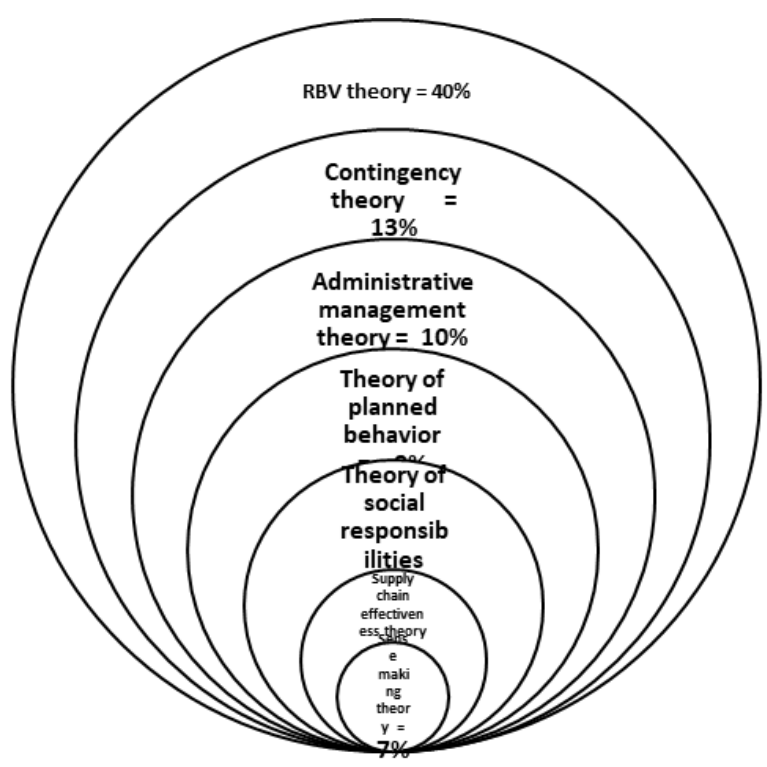

Figure 2. Percentages of management theories linked to sustainable competitiveness based on the latest literature review. Source: created by the authors 
Note, that previous research studies that apply to my paper could be limited, depending on the nature of my research topic in addition to the databases that were exclusively WOS, KJD, RSCI, SCIELO for the timespan equal to the last 5 years ( 2015 -2020), in the English language.

Conducted research results have practical value for SME's as this study analyses the best sustainable strategic management orientation to achieve green competitiveness, which has an impact on organizational performance.

Since there are limited studies on this subject, a whole new typology of research needs to be created. The identification of a deficiency, in this case, can be seen as a significant opportunity to find new gaps in the preliminary literature and the need to grow more in the field of research.

\section{Appendix A}

\section{Management theory detection based on the PRISMA diagram (Fig. 1)}

Table 1. Management theory detection based on the PRISMA diagram (Fig. 1)

\begin{tabular}{|c|c|c|c|c|}
\hline MNG theories and & $\begin{array}{l}\text { TS }=((\text { SYSTEMS } \\
\text { MANAGEMENT AND } \\
\text { THEORIES } *)+\end{array}$ & $\begin{array}{l}\text { (SUSTAINABLE* } \\
\text { MANAGEMENT) } \\
=266 \text { results }\end{array}$ & $\begin{array}{l}+(\text { competitiveness } *) \\
=10 \text { results }\end{array}$ & $\begin{array}{l}\text { MNG theories } \\
\text { + sustainable } \\
\text { management } \\
\text { +competitiveness }\end{array}$ \\
\hline $\begin{array}{l}1184 \text { sys management } \\
\text { theories }(100 \%)\end{array}$ & $\begin{array}{l}\text { All systems management } \\
\text { theories }\end{array}$ & $266(46 \%)$ & 10 & $=23$ \\
\hline $\begin{array}{l}\text { Competitiveness } 146 \\
(12 \%)\end{array}$ & $\begin{array}{l}\text { Contingency management } \\
\text { theory }\end{array}$ & 42 & 3 & $\begin{array}{l}10 \text { competitiveness - } \\
\text { specified systems } \\
\text { management theories }\end{array}$ \\
\hline $\begin{array}{l}\text { Sustainable } \\
\text { management } 574 \\
(48 \%)\end{array}$ & Theory XandY & 6 & 1 & \multirow{6}{*}{ management theories } \\
\hline $\begin{array}{l}\text { Undetected } \\
\text { management theories } \\
=308(54 \%)\end{array}$ & Administrative theory $*$ & 110 & 1 & \\
\hline \multirow{4}{*}{$\begin{array}{l}\text { Detected SM } \\
\text { Theories }=266 \text { results } \\
(46 \%)\end{array}$} & Bureaucratic theory & 8 & 1 & \\
\hline & Human relations theory & 73 & 1 & \\
\hline & Douglas theory & 7 & 0 & \\
\hline & $\begin{array}{l}\text { mixed systems management } \\
\text { theories }\end{array}$ & 20 & $3 \quad$ Artl & \\
\hline
\end{tabular}

Source: created by the authors

\section{References}

Belen, L., and Nuria, V. (2017). Corporate Competitiveness Based on Sustainability and CSR Values: Case Studies of Spanish MNCs (pp. 309-314). Springer, Cham. https://doi.org/10.1007/978-3-319-33865-1_39

Bezerra, P., Arruda, A., Laila, T., and Moroni, I. (2018). Strategic design: Enhancing experiences and developing local products. In Advances in Intelligent Systems and Computing (Vol. 588, pp. 453-461). Springer Verlag. https://doi.org/10.1007/978-3-319-60582-1_45 


\section{INSIGHTS INTO REGIONAL DEVELOPMENT}

ISSN 2669-0195 (online) http://jssidoi.org/jesi/

2021 Volume 3 Number 2 (June)

http://doi.org/10.9770/IRD.2021.3.2(7)

Bhattacharya, S., Momaya, K. S., and Chandrasekhar Iyer, K. (n.d.). Benchmarking enablers to achieve growth performance: a conceptual framework. https://doi.org/10.1108/BIJ-08-2019-0376

Brodowska-Szewczuk, J. 2019. Determinants of the development of enterprises' innovativeness in the aspect of competitiveness of the economy. Enterpreunership and Sustainability Issues, 7(2), 1279-1295. http://doi.org/10.9770/jesi.2019.7.2(33)

Camisón, C. (2020). Competitiveness and sustainability in tourist firms and destinations. Sustainability (Switzerland), 12(6). https://doi.org/10.3390/su12062388

Castagna, F., Centobelli, P., Cerchione, R., Oropallo, E., Shashi, and Strazzullo, S. (2020). Assessing SMEs' Internationalisation Strategies in Action. Applied Sciences, 10(14), 4743. https://doi.org/10.3390/app10144743

Deslatte, A., and Stokan, E. (2020). Sustainability Synergies or Silos? The Opportunity Costs of Local Government Organizational Capabilities. Public Administration Review. https://doi.org/10.1111/puar.13237

Dubey, R., Gunasekaran, A., Childe, S. J., Papadopoulos, T., Hazen, B. T., and Roubaud, D. (2017). International Journal of Production Research Examining top management commitment to TQM diffusion using institutional and upper echelon theories Examining top management commitment to TQM diffusion using institutional and upper echelon theories.

https://doi.org/10.1080/00207543.2017.1394590

Hermans, F. (1861). The potential contribution of transition theory to the analysis of bioclusters and their role in the transition to a bioeconomy. Biofuels, Bioprod. Bioref, 12, 265-276. https://doi.org/10.1002/bbb.1861

Hermans, F. (2018), The potential contribution of transition theory to the analysis of bioclusters and their role in the transition to a bioeconomy. Biofuels, Bioprod. Bioref., 12: 265-276. https://doi.org/10.1002/bbb.1861

Huguenin, A., and Jeannerat, H. (2017). Creating change through pilot and demonstration projects: Towards a valuation policy approach. Research Policy, 46(3), 624-635. https://doi.org/10.1016/j.respol.2017.01.008

Huntley Lewis, E. O. (2019). Environmental regulations and their effect on innovation and competitiveness in tourism in Barbados, Guyana and Jamaica. Worldwide Hospitality and Tourism Themes, 11(2), 147-154. https://doi.org/10.1108/whatt-12-2018-0085

Ju, Y., Wang, Y., Cheng, Y., and Jia, J. (2019). Investigating the impact factors of the logistics service supply chain for sustainable performance: Focused on integrators. Sustainability (Switzerland), 11(2). https://doi.org/10.3390/su11020538

Kodama, M. (2017). Developing strategic innovation in large corporations-The dynamic capability view of the firm. Knowledge and Process Management, 24(4), 221-246. https://doi.org/10.1002/kpm.1554

Kokkonen, K., and Ojanen, V. (2018). From opportunities to action - An integrated model of small actors' engagement in bioenergy business. Journal of Cleaner Production, 182, 496-508. https://doi.org/10.1016/j.jclepro.2018.02.013

Nevárez, V. L., and Féliz, B. D. Z. (2019). Social responsibility in the dimensions of corporate citizenship. A case study in agricultural manufacturing. CIRIEC-Espana Revista de Economia Publica, Social y Cooperativa, (97), 179-211. https://doi.org/10.7203/CIRIECE.97.12566

Sampurna Panigrahi, S., Bahinipati, B., and Jain, V. (n.d.). Sustainable supply chain management. A review of literature and implications for future research. Management of Environmental Quality ISSN: 1477-7835 Article publication date: 8 June 2018 https://doi.org/10.1108/MEQ-01-2018-0003

Valaei, N. (n.d.). Organizational structure, sense making activities and SMEs' competitiveness An application of confirmatory tetrad analysis-partial least squares (CTA-PLS). VINE Journal of Information and Knowledge Management Systems ISSN: 2059-5891Article publication date: 13 February 2017 https://doi.org/10.1108/VJIKMS-04-2016-0015

Vinícius, R., Jordão, D., Novas, J., and Gupta, V. (2020). The role of knowledge-based networks in the intellectual capital and organizational performance of small and medium-sized enterprises, 49(1), 116-140. https://doi.org/10.1108/K-04-2019-0301

Wong, W. P., Soh, K. L., and Chong, C. Le. (2016). Differentiated service consumption and low cost production: Striking a balance for a sustainable competitive advantage in Malaysia. International Journal of Production Economics, 181, 450-459.

https://doi.org/10.1016/j.ijpe.2015.09.029 
INSIGHTS INTO REGIONAL DEVELOPMENT

ISSN 2669-0195 (online) http://jssidoi.org/jesi/

2021 Volume 3 Number 2 (June)

http://doi.org/10.9770/IRD.2021.3.2(7)

\section{Nour NASSAR}

ORCID ID: orcid.org/0000-0003-0257-9186

\section{Manuela TVARONAVIČIENE}

ORCID ID: orcid.org/0000-0002-9667-3730

Make your research more visible, join the Twitter account of INSIGHTS INTO REGIONAL DEVELOPMENT:

@IntoInsights

Copyright (C) 2021 by author(s) and VsI Entrepreneurship and Sustainability Center

This work is licensed under the Creative Commons Attribution International License (CC BY).

http://creativecommons.org/licenses/by/4.0/

c) (†) Open Access 